\title{
Government spending in a new Keynesian endogenous growth model
}

Citation for published version (APA):

Kuehn, S., Muysken, J., \& van Veen, A. P. (2010). Government spending in a new Keynesian endogenous growth model. METEOR, Maastricht University School of Business and Economics. METEOR Research Memorandum No. 001 https://doi.org/10.26481/umamet.2010001

Document status and date:

Published: 01/01/2010

DOI:

10.26481/umamet.2010001

Document Version:

Publisher's PDF, also known as Version of record

\section{Please check the document version of this publication:}

- A submitted manuscript is the version of the article upon submission and before peer-review. There can be important differences between the submitted version and the official published version of record.

People interested in the research are advised to contact the author for the final version of the publication, or visit the DOI to the publisher's website.

- The final author version and the galley proof are versions of the publication after peer review.

- The final published version features the final layout of the paper including the volume, issue and page numbers.

Link to publication

\footnotetext{
General rights rights.

- You may freely distribute the URL identifying the publication in the public portal. please follow below link for the End User Agreement:

www.umlib.nl/taverne-license

Take down policy

If you believe that this document breaches copyright please contact us at:

repository@maastrichtuniversity.nl

providing details and we will investigate your claim.
}

Copyright and moral rights for the publications made accessible in the public portal are retained by the authors and/or other copyright owners and it is a condition of accessing publications that users recognise and abide by the legal requirements associated with these

- Users may download and print one copy of any publication from the public portal for the purpose of private study or research.

- You may not further distribute the material or use it for any profit-making activity or commercial gain

If the publication is distributed under the terms of Article $25 \mathrm{fa}$ of the Dutch Copyright Act, indicated by the "Taverne" license above, 


\section{Maastricht University}

Stefan Kühn, Joan Muysken, Tom van Veen

Government Spending in a New Keynesian Endogenous Growth Model

RM/10/001

\section{METEOR}

Maastricht University School of Business and Economics

Maastricht Research School of Economics

of Technology and Organization

\section{P.O. Box 616}

NL - 6200 MD Maastricht

The Netherlands 


\title{
Government Spending in a New Keynesian Endogenous Growth Model
}

\author{
Stefan Kühn* Joan Muysken ${ }^{\dagger} \quad$ Tom van Veen ${ }^{\ddagger}$ \\ January 19, 2010
}

WORKING PAPER

\begin{abstract}
Standard New Keynesian models cannot generate the widely observed result that private consumption is crowded in by government spending. We use a New Keynesian endogenous growth model with endogenous labour supply to analyse this phenomenon. The presence of small direct productivity effects of government spending as well as Calvo pricing and a Taylor monetary policy rule significantly enhance the growth rate effect of temporary government spending. The resulting model can explain the consumption crowding-in phenomenon for realistic parameter values. We also find plausible values for the government spending multiplier.
\end{abstract}

JEL Classification: E20, E62, O40

Keywords: New Keynesian Macroeconomics, Endogenous Growth, Crowding in, Spending Multiplier

\footnotetext{
${ }^{*}$ Corresponding Author. Department of Economics, Maastricht University, P.O. Box 616, 6200MD Maastricht, The Netherlands, E-Mail: s.kuehn@maastrichtuniversity.nl

${ }^{\dagger}$ Maastricht University

${ }^{\ddagger}$ Maastricht University and Nyenrode School of Accountancy and Controlling, Nyenrode Business University, The Netherlands
} 


\section{Introduction}

Under what conditions will a temporary government spending shock increase the economy's rate of growth? Higher growth will lead to a level effect for private consumption, raising it above the baseline scenario level. This is called crowding in of consumption by government spending, a phenomenon frequently observed in empirical research (Blanchard and Perotti, 2002; Burnside et al., 2004; Castro, 2006; Galí et al., 2007; Perotti, 2007). This observation contrasts with the prediction of the neoclassical RBC model (Baxter and King, 1993) as well as a standard New Keynesian model (Linnemann and Schabert, 2003b). In Kühn et al. (2009) we show that various extensions of household behaviour, e.g. including a preference for government expenditure in the utility function (Linnemann and Schabert, 2003a) or introducing rule-of-thumb consumer behaviour (Galí et al., 2007), are not able to explain this phenomenon in a satisfactory way.

In this paper we explore a new route by applying three well established mechanisms that in combination will lead to consumption crowding in a few periods after a temporary government spending shock: endogenous growth, productive government spending and New Keynesian deviations from the flexible price equilibrium.

The relationship between fiscal policy, both taxation and spending, and growth has been analysed extensively for permanent changes in the comparison of steady states. Turnovsky (2000) finds that increases in distortional taxation tend to reduce growth, while increases in both productive and non-productive government spending increase growth.

While temporary government spending will generally work through the same mechanisms as permanent government spending to increase growth, the temporary negative wealth effect induces households to temporarily save less and consume more to smooth their consumption over time. This effect tends to reduce growth. We derive analytically under which conditions the growth increasing effect of government spending dominates the consumption smoothing effect of households. In general, we find that the effect depends on duration of the shock and on the labour supply response, which is similar to the finding of Chang (1999) concerning capital accumulation in a standard RBC model without endogenous growth.

We find that under certain conditions a basic flexible price model of endogenous growth 
without productive government spending could lead to higher growth and thus a positive level effect in private consumption, although these conditions are very restrictive. When we allow for productivity effects of government spending, these conditions relax significantly. We can thus obtain a significant positive effect on private consumption under standard parameter settings.

A novel aspect in the analysis of the effects of temporary government spending is the introduction of Calvo (1983) price stickiness, the New Keynesian Phillips curve as well as a Taylor monetary policy rule in a model of endogenous growth. ${ }^{1}$ If the central bank increases the interest rate above its flexible price level in response to output deviations from steady state, growth will be increased even further, resulting in stronger consumption crowding in.

The current economic crisis has lead to a renewed discussion on the size of government spending multipliers. A recent overview paper written by Hall (2009) surveys empirical findings on the size of fiscal multipliers as well as it discusses model extensions to obtain a multiplier of a certain size. However, the standard New Keynesian model always produces a lower medium run multiplier than the impact multiplier, while empirically the opposite can be found (Galí et al., 2007; Perotti, 2007). The additional growth induced by government spending in the setup of the endogenous growth model allows medium run multipliers to exceed impact multipliers. Combined with the consumption crowdingin capabilities, this fact makes the New Keynesian endogenous growth model a serious alternative to the standard New Keynesian model for the analysis of temporary fiscal policy.

In Section 2 we present the flexible price model model of endogenous growth with productive government spending and analyse its dynamics in Section 3. The New Keynesian extension of the growth model and the implications for the impact of fiscal policy are discussed in Section 4. In Section 5 we present some simulation results of the extended model to illustrate its consumption crowding in potential. Section 5.2 discusses the output multipliers of the New Keynesian endogenous growth model and compares them to a standard New Keynesian model. Section 6 concludes.

\footnotetext{
${ }^{1}$ We only know of papers employing a New Keynesian growth model in the analysis of monetary policy, i.e.: Rannenberg (2008), Hiroki (2009)
} 


\section{The Endogenous Growth Model}

In this section we present a flexible price endogenous growth model with productive government spending. This enables us to analyse the impact of government spending in a way that allows for consumption crowding in, as we show in the next section.

\subsection{Productive Government Spending and Endogenous Growth}

The endogenous growth model we employ follows Romer (1986). The idea is that capital accumulation generates aggregate knowledge available for all firms, so that even though capital faces diminishing returns on the firm level, it exhibits constant returns on the aggregate level. Therefore, there is no limit to capital accumulation. We combine this notion with an insight of Barro (1990), who also uses a production function where firms face diminishing returns to capital, but where government spending provides productive services so that on aggregate returns to capital are constant again.

The use of productive government spending as the additional accumulated resource to generate endogenous growth is common practice in the literature. Furthermore, there is ample evidence that government activity is indeed productive - see Romp and de Haan (2007) and Bom and Lighthart (2008) for recent surveys of the literature. They also discuss whether public capital stock or government spending flows must be used in the production function and conclude that both stocks and flows are used in the analyses. Most authors assume a proportional relation between the productivity of the capital stock and of the spending flows. For example, Turnovsky (1997) noted that the public capital stock rather than government flow spending should be used in the production function. Nevertheless, he uses flow spending in a model with endogenous labour supply in Turnovsky (2000).

There are several reasons why that is preferable. First, there are clearly elements of government flow spending, like security, that directly ensure the productivity of private capital without amending to a stock. Second, a model with a public capital stock needs constant flow spending to counter depreciation of that capital stock, so that in steady state both types of analysis yield the same conclusions. Third, using flow spending makes the model analytically more tractable since an additional capital stock complicates the 
analysis of the dynamics considerably. For these reasons we also use the flow approach to derive clear analytical results. ${ }^{2}$

\subsection{Production}

We specify the production function for firm $i$ in period $t$ as a Cobb-Douglas function

$$
Y_{t}^{i}=A\left(K_{t}^{i}\right)^{\alpha}\left(L_{t}^{i}\right)^{1-\alpha} T F P_{t}\left(K_{t}, G_{t}\right)
$$

The variables $Y_{t}^{i}, K_{t}^{i}$ and $L_{t}^{i}$ represent output, capital and employment, respectively. Total factor productivity $T F P_{t}$ is identical for all firms and represents on the one hand technological spillovers (following Romer, 1986), for simplicity represented by the level of aggregate capital $K_{t}$, and on the other hand the productive effect government spending $G_{t}$ (following Barro, 1990). To simplify notation, we specify:

$$
T F P_{t}=K_{t}^{\epsilon} G_{t}^{\gamma}
$$

Government spending is a constant share $\theta$ of output, which implies the spending rule

$$
G_{t}=\theta Y_{t}
$$

Assuming identical firms, the aggregate production function is

$$
Y_{t}=\sum_{i=1}^{n} Y_{t}^{i}=\left(A \theta_{t}^{\gamma}\right)^{\frac{1}{1-\gamma}} K_{t}^{\frac{\alpha+\epsilon}{1-\gamma}} L_{t}^{\frac{1-\alpha}{1-\gamma}}
$$

Endogenous growth requires that the marginal product of the accumulated resource, capital, does not diminish as it accumulates. We therefore assume $\epsilon=1-\alpha-\gamma$ to hold.

Romp and de Haan (2007) find in their survey of the literature that the elasticity of output with respect to government spending $(\gamma)$ lies between 0 and 0.4 , where more recent research results indicate that it should be at the lower end of this margin. Bom

\footnotetext{
${ }^{2}$ For illustrative purposes, we also simulate a model with a government capital stock in section 5 , where we conclude that qualitative results are not affected.
} 
and Lighthart (2008) estimate in their Meta analysis of different studies a $\gamma$ of $0.086 .^{3}$ This implies that $\gamma$ should not exceed 0.1 if one wants the model to imply a realistic productivity effect of government spending.

\subsection{The Firms}

Each firm i minimises costs $r_{t}^{k} K_{t}^{i}+w_{t} L_{t}^{i}$ subject to output produced. The variables $r_{t}^{k}$ and $w_{t}$ represent the return on capital in use and the wage rate, respectively, in period $t$. The firm takes $r_{t}^{k}$ and $w_{t}$ as given. Solving the Lagrangian and interpreting the Lagrange multiplier as marginal cost $m c$, we obtain the first order conditions:

$$
\begin{aligned}
r_{t}^{k} & =m c_{t} \alpha \frac{Y_{t}^{i}}{K_{t}^{i}} \\
w_{t} & =m c_{t}(1-\alpha) \frac{Y_{t}^{i}}{L_{t}^{i}}
\end{aligned}
$$

Aggregating across all identical firms and using equation (4), equations (5a) and (5b) become

$$
\begin{aligned}
& r_{t}^{k}=m c_{t} \alpha\left(A \theta^{\gamma}\right)^{\frac{1}{1-\gamma}} L_{t}^{\frac{1-\alpha}{1-\gamma}} \\
& w_{t}=m c_{t}(1-\alpha)\left(A \theta^{\gamma}\right)^{\frac{1}{1-\gamma}} K_{t} L_{t}^{-\frac{\alpha-\gamma}{1-\gamma}}
\end{aligned}
$$

Following a standard set-up of monopolistic competition as described in Woodford (2003), firms set their prices as a desired mark-up $\mu>1$ over their real marginal cost. In a flexible price steady state this mark-up is constant and depends on the elasticity of demand that firms face; a higher elasticity of demand corresponds to a lower mark-up. ${ }^{4}$ The result is that under symmetric firms holds

$$
m c_{t}=\frac{1}{\mu}
$$

\footnotetext{
${ }^{3}$ In fact, they survey the elasticity of output with respect to public capital. However, a constant public capital stock requires flow investment of $I^{G}=\delta K^{G}$, where $\delta$ is depreciation. Substituting this for $K^{G}$ in a production function shows that flow spending has the same elasticity as the capital stock in steady state.

${ }^{4}$ For simplicity we do not present here the full model including the distinction between an intermediate goods and a final goods sector - for the full model see Woodford (2003).
} 


\subsection{Households}

The representative household maximises its intertemporal utility over consumption $C$ and leisure $\Lambda$ subject to a budget constraint and a capital accumulation equation. This can be specified as follows:

$$
\max _{C, \Lambda} \sum_{t=0}^{\infty} \beta^{t} u_{t}(C, \Lambda)
$$

where $\beta<1$ is the time discount factor. Since the household's available time is bounded, we need the representative household to supply a constant number of hours when real wage is growing. Therefore, income and substitution effects must be exactly offsetting. We restrict our attention to the commonly used CES function with log-utility for consumption. We furthermore use the common specification of introducing labour supply $L$ directly in the utility function, where $L=1-\Lambda$ when we normalise total available time to unity. We thus obtain

$$
u_{t}=\log \left(C_{t}\right)-\frac{L_{t}^{1+\sigma}}{1+\sigma}
$$

where $\sigma>0$ is the inverse of the intertemporal elasticity of labour supply.

Utility is maximised subject to the budget constraint and the capital accumulation identity

$$
\begin{gathered}
w_{t} L_{t}+\left(R_{t}\right) B_{t} / P_{t}+r_{t}^{k} K_{t}+\kappa_{t} \geq C_{t}+\tau_{t}+B_{t+1} / P_{t}+I_{t}, \\
K_{t+1}=(1-\delta) K_{t}+I_{t},
\end{gathered}
$$

where $\kappa_{t}$ are profits from firm ownership of households, $\tau_{t}$ lump sum taxes, $R_{t}$ the gross nominal interest rate in period $t$ and $\delta$ is the capital depreciation rate. $C_{t}$ is consumption, $I_{t}$ is investment, $P_{t}$ is the price level and $B_{t}$ is the stock of bonds in period $t .^{5}$ Government spending uses resources that are unavailable to households, either through direct taxation or indirectly by households buying government bonds. We only deal with lump sum

\footnotetext{
it.

${ }^{5}$ The stock of bonds in the economy was issued by the government, which pays interest $i=R-1$ on
} 
taxation, meaning that any debt owed by the government to households can simply be repaid by taxing households that amount, thereby implying Ricardian equivalence. Thus, a fiscal financing rule is not needed.

Household optimisation leads to the following first order conditions:

$$
\begin{aligned}
C_{t} & =C_{t+1} \frac{1}{\beta} \frac{\pi_{t+1}}{R_{t+1}} \\
r_{t+1}^{k} & =\frac{R_{t+1}}{\pi_{t+1}}+\delta-1 \\
w_{t} & =L_{t}^{\sigma} C_{t}
\end{aligned}
$$

Equation 11a is the standard Euler equation, showing the intertemporal consumption path depending on the real interest rate. $\frac{R}{\pi}$ represents the real interest rate on bonds, where $\pi_{t+1}=\frac{P_{t+1}}{P_{t}}$ is the gross inflation rate. Arbitrage ensures that the real interest rate on bonds equals the real return on capital. Condition (11c) shows the equality between the marginal utility of consumption and leisure, where the relative price of leisure in terms of consumption is the real wage. Inelastic labour supply then results when $\sigma \rightarrow \infty$.

\subsection{The Complete Model}

Demand for labour and labour supply, equations $6 \mathrm{~b}$ and $11 \mathrm{c}$ respectively, determine the labour market equilibrium. This yields:

$$
L_{t}=\left(\frac{m c_{t}(1-\alpha)\left(A \theta^{\gamma}\right)^{\frac{1}{1-\gamma}}}{\frac{C_{t}}{K_{t}}}\right)^{\frac{1-\gamma}{\sigma+\alpha-\gamma(1+\sigma)}}
$$

We restrict $\gamma$ to

$$
\gamma<\frac{\alpha+\sigma}{1+\sigma}
$$

Without this restriction one might find $\frac{\partial L}{\partial x} \rightarrow \infty$, where $x$ could be $m c, A$ or $\theta$. A shock increasing labour supply will increase output, which in turn increases government spending (see equation 3). When government spending is too productive, the following increase in labour productivity is so strong that the large rise in real wages leads to an 
exploding behaviour of labour supply.

Using the resource constraint $Y=C+I+G$ as well as the definition of the growth rate of capital $g_{t}=\frac{K_{t}}{K_{t-1}}-1$, the full flexible price model then can be represented by the following system of 6 equations:

$$
\begin{aligned}
\frac{Y_{t}}{K_{t}} & =m c_{t}^{c_{1}}(1-\alpha)^{c_{1}}\left(A \theta_{t}^{\gamma}\right)^{\frac{1}{1-\gamma}\left(1+c_{1}\right)}\left(\frac{C_{t}}{K_{t}}\right)^{-c_{1}} \\
\frac{C_{t}}{K_{t}} & =\frac{C_{t+1}}{K_{t+1}}\left(1+g_{t+1}\right) \frac{1}{\beta} \frac{1}{1-\delta+r_{t+1}^{k}} \\
g_{t+1} & =\frac{I_{t}}{K_{t}}-\delta \\
\frac{I_{t}}{K_{t}} & =\left(1-\theta_{t}\right) \frac{Y_{t}}{K_{t}}-\frac{C_{t}}{K_{t}} \\
r_{t}^{k} & =m c_{t}^{1+c_{1}} \alpha(1-\alpha)^{c_{1}}\left(A \theta^{\gamma}\right)^{\frac{1}{1-\gamma}}\left(1+c_{1}\right)\left(\frac{C}{K}\right)^{-c_{1}} \\
m c_{t} & =\frac{1}{\mu} \\
\text { with } & \\
c_{1} & =\frac{1-\alpha}{\sigma+\alpha-\gamma(1+\sigma)}>0 .
\end{aligned}
$$

We analyse the dynamics of this model in the next section.

\section{Analysis of the Flexible Price Endogenous Growth Model}

We analytically derive the dynamics involved when a temporary government spending shock affects the economy, where the focus lies on the impact on the economy's growth rate. First, we analyse how a permanent government spending shock affects the growth rate of the economy to illustrate the mechanisms at work in the model. We do this by deriving the steady state growth rate in Section 3.1 and the dynamic process around the steady state in Section 3.2. The impact of a temporary shock in government spending is discussed in Section 3.3. 


\subsection{Steady State}

The steady state is the flexible price equilibrium when $Y, K, C, I$ and $w$ all grow at a constant rate of growth, $g$. By imposing $\Delta \frac{C}{K}=0$ on equation $14 \mathrm{~b}$ and using equation $6 \mathrm{a}$ we obtain an expression relating steady state growth to the steady state labour supply. ${ }^{6}$

$$
g=\beta\left(1+\frac{\alpha}{\mu}\left(A \theta^{\gamma}\right)^{\frac{1}{1-\gamma}} L^{\frac{1-\alpha}{1-\gamma}}-\delta\right)-1
$$

Steady state labour supply, as long as it is elastic (i.e. $\sigma$ is finite), can be identified implicitly as in Turnovsky (2000). Labour supply determines output as well as the return to capital, which in turn determines the steady state growth and thus investment, leaving resources available for consumption after subtracting government spending. This consumption has to be such that it induces households to supply exactly that amount of labour that delivers that consumption. The resulting consumption and leisure have to match the resource constraint. An increase in government spending share $\theta$ then increases labour supply because of the negative effect on consumption, and thus its influence on the substitution between consumption and leisure.

Lemma 3.1 A permanent increase of the share or government spending in output $(\theta)$ leads to a permanent increase in growth if either (a) government spending is productive $(\gamma>0)$ or (b) labour supply is elastic (i.e. $\sigma$ is finite), or both (a) and (b) hold.

Proof (a) follows immediately from equation 15 (and from the positive impact of $\theta$ on labour supply, as long as it is elastic). (b) follows from the identification of the steady state labour supply. If we make the approximation $(1-\beta)(1-\delta) \approx 0$, we can explicitly solve for steady state labour supply.

$$
L=\left(\frac{\frac{1-\alpha}{\alpha \beta}}{a_{2}-1}\right)^{\frac{1}{1+\sigma}}
$$

with

$$
a_{2}=\frac{(1-\theta) \mu}{\alpha \beta}
$$

\footnotetext{
${ }^{6}$ This equation is in line with the steady state growth rate $g=A \alpha L^{1-\alpha}-\delta-\rho$ found for the standard AK model with exogenous labour supply, see for instance Barro and Sala-i-Martin (1995), where $\beta=\frac{1}{1+\rho}$.
} 
Equation 16 immediately proves point (b). ${ }^{7}$

An increase in government spending share $\theta$ increases the growth rate in two ways. On the one hand it increases labour supply, as we argued above. This in turn raises the marginal product of capital and thus the real interest rate - this is the effect analysed in Turnovsky (2000). On the other hand, more productive government spending directly raises the return to capital. The higher interest rate induces households to save more, thus creating more steady state growth - this is the effect analysed in Barro (1990).

\subsection{Dynamics around the Steady State}

The usual procedure for the analysis of dynamics of a model around the steady state is the evaluation of a Taylor expansion around that steady state. We will also follow that approach later on. However, we first show the precise dynamic equations for the flexible price model.

We reduce the flexible price model (equations 14a to 14f) to two equations that can be represented in the $(C / K, g)$ space, see Figure 1a.

$$
\begin{aligned}
g_{t+1} & =\left(1-\theta_{t}\right)\left(\frac{1-\alpha}{\mu}\right)^{c_{1}}\left(A \theta_{t}^{\gamma}\right)^{\frac{1}{1-\gamma}\left(1+c_{1}\right)}\left(\frac{C_{t}}{K_{t}}\right)^{-c_{1}}-\frac{C_{t}}{K_{t}}-\delta \\
\frac{C_{t}}{K_{t}} & =\frac{C_{t+1}}{K_{t+1}}\left(1+g_{t+1}\right) \frac{1}{\beta} \frac{1}{1-\delta+\frac{\alpha}{\mu}\left(\frac{1-\alpha}{\mu}\right)^{c_{1}}\left(A \theta_{t+1}^{\gamma}\right)^{\frac{1}{1-\gamma}\left(1+c_{1}\right)}\left(\frac{C_{t+1}}{K_{t+1}}\right)^{-c_{1}}}
\end{aligned}
$$

Equation (17a) reflects the intratemporal choice of consumption and labour supply as well as the resource constraint, which we represent as the $G G$ curve. A higher current level of consumption lowers labour supply via the consumption leisure trade-off. This lowers output, and thus resources available for investment and growth. Furthermore, higher consumption directly uses resources for growth. Thus, the $G G$ curve is downward sloping in the $(C / K, g)$-plane. This curve will shift to the left when the government uses more resources. ${ }^{8}$

\footnotetext{
${ }^{7}$ We obviously need $a_{2}>1$, hence $\theta<1-\frac{\alpha \beta}{\mu}$.

${ }^{8}$ It is actually possible for the $G G$ curve to shift to the right upon a government spending increase when output increases by more than government spending. This is the case when $\frac{1-\theta}{\theta} \frac{\gamma}{1-\gamma}\left(1+c_{1}\right)>1$. The part $\frac{1-\theta}{\theta} \frac{\gamma}{1-\gamma}$ of this condition is the direct productivity impact of government spending. The part $1+c_{1}$ is the labour supply effect of productive government spending.
} 
Equation (17b) represents the intertemporal consumption smoothing objective of households, which we represent as the $C C$ curve. It contains essentially two arguments: future consumption and the real interest rate. Since higher growth raises the absolute level of future consumption given $C / K$, the curve is upward sloping in in the $(C / K, g)$-plane. Furthermore, a change in future $C / K$, shifts the curve upward.

Finally, as in a standard model, the real interest rate plays a role in intertemporal consumption substitution. The real interest rate depends on next period's return to capital, which in turn depends positively on labour supply and therefore negatively on consumption. Therefore, the $C C$ curve in the flexible price model can be represented as depending only positively on future consumption. ${ }^{9}$

An increase in productive government expenditures raises the return to capital, thereby increasing the real interest rate and shifting the $C C$ curve down, ceteris paribus. When government spending is not productive, it does not directly affect the $C C$ curve.

The steady state relationship for a stable consumption path is defined by setting $\Delta \frac{C}{K}=0$ in equation $(17 \mathrm{~b})$, which yields:

$$
\frac{C}{K}=\left(\frac{\frac{\alpha}{\mu}\left(\frac{1-\alpha}{\mu}\right)^{c_{1}}\left(A \theta^{\gamma}\right)^{\frac{1}{1-\gamma}\left(1+c_{1}\right)}}{\frac{1+g}{\beta}-1+\delta}\right)^{\frac{1}{c_{1}}}
$$

The $\Delta(C / K)=0$ curve shows possible combinations of consumption level and growth consistent with a constant level of consumption per unit of capital on the steady state growth path. The slope of the $\Delta(C / K)=0$ shows the reaction of the real interest rate to a change in consumption via the labour supply response. Note that a higher rate of growth requires a higher real interest rate for households to save sufficiently. In case of elastic labour supply the return to capital increases upon a fall in consumption, inducing higher growth. As a consequence the $\Delta(C / K)=0$ curve is downward sloping, but it is steeper that the $G G$ curve. ${ }^{10}$ When labour supply is inelastic, the $\Delta(C / K)=0$ curve is vertical.

\footnotetext{
${ }^{9}$ Under sticky prices, with the interest rate not directly connected to consumption and labour supply, the real interest rate enters as an additional argument in the $C C$ curve.

${ }^{10}$ Proof: For $\Delta \frac{C}{K}=0: \frac{d(C / K)}{d g}=-\frac{1}{c_{1} \frac{(1-\theta) Y / K}{C / K} \frac{1}{a_{2}}}$. For GG: $\frac{d(C / K)}{d g}=-\frac{1}{c_{1} \frac{(1-\theta) Y / K}{C / K}+1}$. Since $a_{2}>1$, the latter slope is clearly flatter.
} 
Similar to the $C C$ curve, the $\Delta(C / K)=0$ curve will shift to the right when government expenditures increase, as long as government expenditures are productive. The more productive government expenditures are, the stronger the curve will shift to the right.

\section{Figure 1}

(a) The basic phase diagram

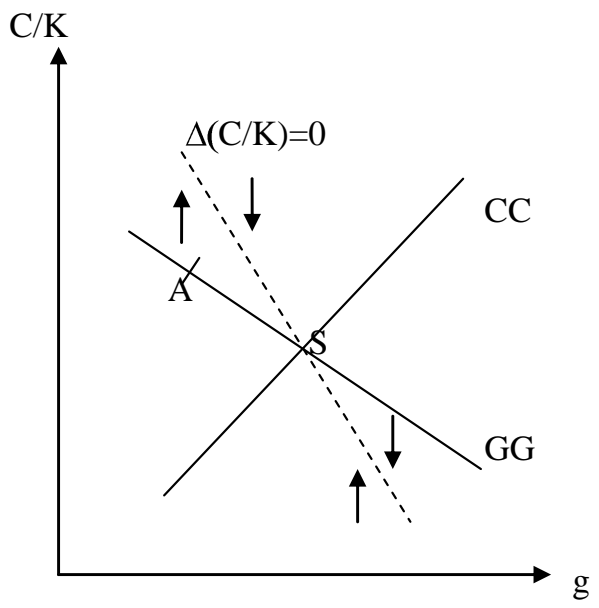

(b) A government spending shock $(\gamma=0)$

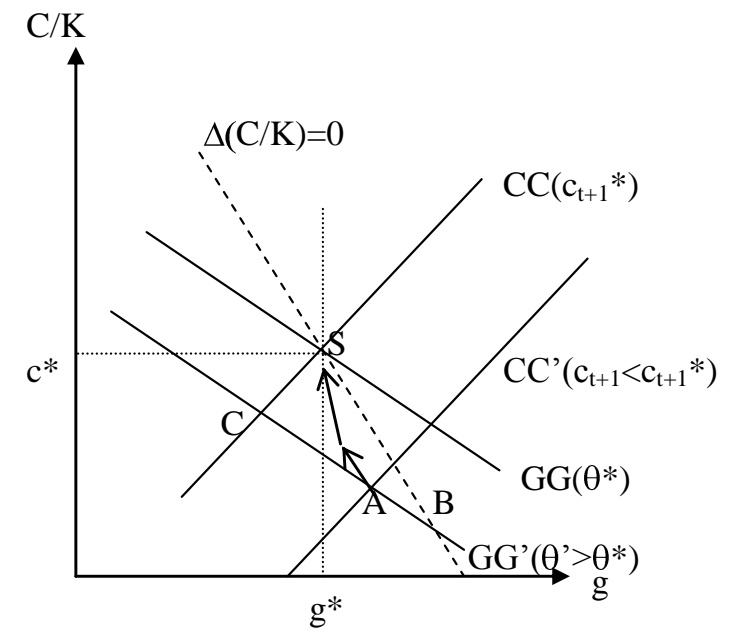

In steady state the consumption growth trade-off given by the $\Delta(C / K)=0$ curve has to be consistent with the resource constraint given by the the $G G$ curve. Therefore, their intersection $S$ in Figure 1a determines the steady state equilibrium. The instantaneous equilibrium is always given by the intersection of the $C C$ and the $G G$ curves. When this intersection is at point $S$, then by construction $\Delta(C / K)=0$.

For a given set of parameters that keep the position of the $G G$ curve unchanged, the model will always be on its steady state growth path. A hypothetical intersection of $C C$ and $G G$ at any other point than $\mathrm{S}$, like $\mathrm{A}$ in Figure 1a, implies $\Delta(C / K)>0$, meaning that households expect an upward sloping consumption path when normalised for capital growth. Since this is inconsistent with the required movement to point $S$, point $A$ cannot be a rational expectations equilibrium and households will choose consumption and growth so that the economy is at point $S$ when there is no expected shift of the $G G$ curve. The immediate jump onto the steady state growth path is a feature that is found in the simple $A K$ model (see Barro and Sala-i-Martin, 1995) as well as in models with endogenous labour supply (Turnovsky, 2000). 


\subsection{The Impact of Increased Government Spending}

We model a temporary government spending shock as an autoregressive shock to the share of government spending in output, $\theta$, so that

$$
\hat{\theta}_{t}=\rho_{\theta} \hat{\theta}_{t-1} \quad 0 \leq \rho_{\theta} \leq 1 .
$$

Graphically, this implies an immediate shift of the $G G$ curve to $G G^{\prime}$ in Figure 1b - where for the sake of exposition we assume $\gamma=0$ - and thereafter a gradual shift back to the original position $G G$ over time. Due to the negative wealth effect on future consumption induced by a persistent $\left(\rho_{\theta}>0\right)$ shock the $C C$ curve also shifts down. The more persistent the shock is, the larger is the shift. A permanent shock shifts it to point $B$, while a one period shock does not shift it, implying a short run equilibrium at point $C$. The actual intersection point $A$, and therefore the question whether growth increases or decreases, depends on a number of parameters. As the government spending shock fades away, the economy returns along the arrows back to the steady state.

To analyse under what conditions a temporary government spending shock increases growth we linearise the model around its steady state using a first order Taylor approximation. The resulting equations can be seen in Appendix A. We use the method of undetermined coefficients to solve the model analytically.

Lemma 3.2 A temporary government spending shock temporarily increases growth and thus induces a permanent positive level effect on $C, Y$ and $K$ if either labour supply is sufficiently elastic, or government spending is sufficiently productive, or a combination of both.

(a). When government spending is unproductive, meaning $\gamma=0$, then the inverse elasticity of labour supply needs to fulfill the condition

$$
\sigma<(1-\alpha) \frac{\rho_{\theta}}{1-\rho_{\theta}}\left(1-\beta \frac{1-\delta}{1+g}\right)-\alpha
$$

to allow higher temporary growth. 
(b). When labour supply is exogenous, meaning $\sigma \rightarrow \infty$, then government spending productivity needs to fulfill the following condition

$$
\frac{\gamma}{1-\gamma}>\frac{\left(1-\rho_{\theta}\right) a_{2}}{\left(a_{2}-\rho_{\theta}\right)\left(1-\rho_{\theta} \frac{1-\delta}{1+g}\right)+\rho_{\theta}\left((1-\beta) a_{2}+\left(1-\rho_{\theta}\right)\right) \frac{1-\delta}{1+g}} \frac{\theta}{1-\theta}
$$

to allow a higher temporary growth.

Proof We define $\hat{c}_{t}=\varphi_{1} \hat{\theta}_{t}$ and $\hat{g}_{t+1}=\varphi_{2} \hat{\theta}_{t}$. We specify the government spending shock according to equation (19). The impact responses of $C$ and $g$ to a shock in $\theta$ are defined by

$\varphi_{1}=-\frac{A_{12}}{A_{11}-\rho_{\theta}}$

$\varphi_{2}=\frac{1+g}{g} \frac{\left(a_{1} a_{2}\left(1+c_{1}\right)-\frac{g+\delta}{1+g}\right) \rho_{\theta} a_{1} c_{2} \frac{\gamma}{1-\gamma}+\left(\rho_{\theta} a_{1} c_{1}-\left(1-\rho_{\theta}\right)\right) a_{1} a_{2}\left(\frac{\theta}{1-\theta}\left(c_{2}-1\right)-\frac{\gamma}{1-\gamma} c_{2}\right)}{\left(A_{11}-\rho_{\theta}\right)\left(c_{2}-\left(1-a_{1}\right)\right)}$

where all parameters are defined in Appendix A.

Conditions (20) and (21) follow directly from equation (22b) by setting $\gamma=0$ or $\sigma \rightarrow \infty$, respectively. Furthermore, it can be shown that

$$
\frac{\partial \varphi_{2}}{\partial \gamma}>0
$$

Figure 2 illustrates how an increase in $\gamma$ increases the range of allowable $\sigma$ for a positive reaction of growth to the temporary government spending shock. The intercepts with $\gamma=0$ and $\sigma \rightarrow \infty$ are given by conditions 20 and 21 .

A temporary government spending shock primarily induces households to reduce saving since they want to smooth consumption over this temporary fall in resources. The more persistent the government spending shock (higher $\rho_{\theta}$ ), the less strong this consumption smoothing motive will be, since next period's consumption is lower as well. The loss in resources leads to a fall in consumption possibilities, which then induces agents to work more. The increase in labour supply on one hand increases the return to capital, and thus 


\section{Regions of Crowding In}

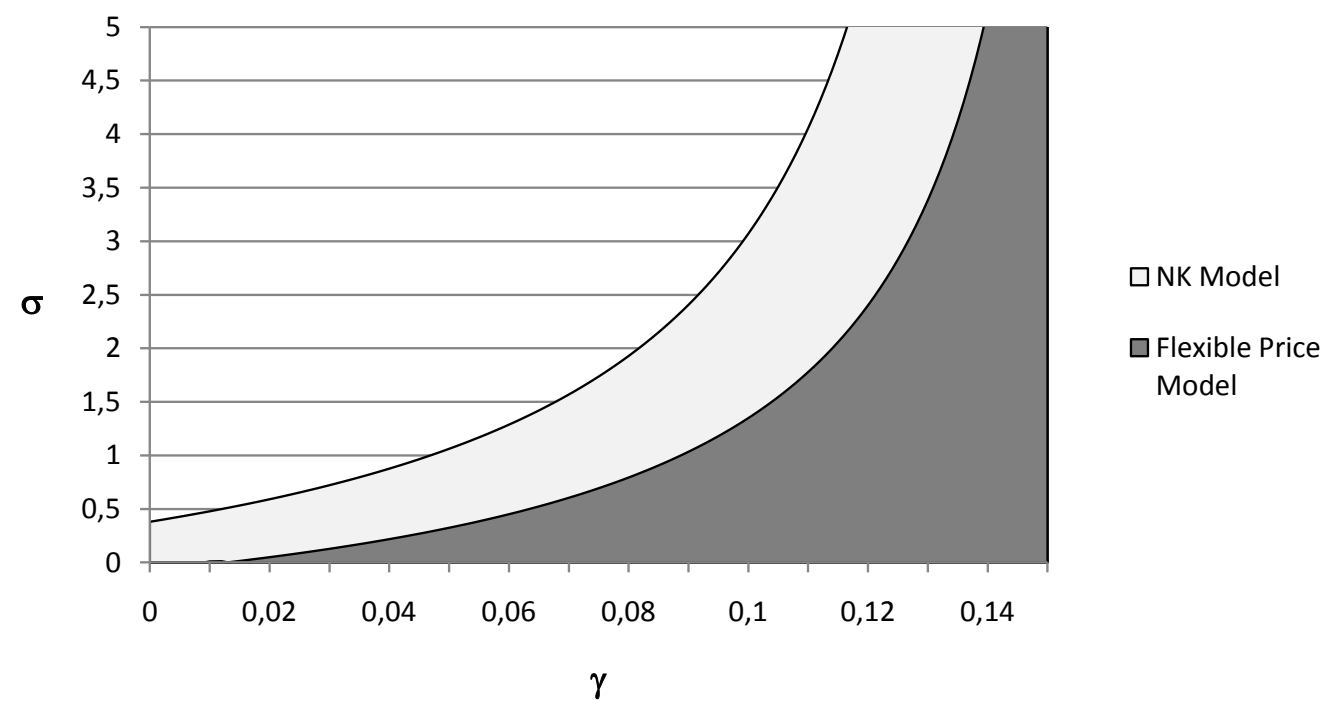

Figure 2: The shaded area represent the regions of parameter combinations of $\gamma$ and $\sigma$ where growth increases following a temporary government spending shock. An increase in $\sigma$ requires an increase in $\gamma$ to counter the lower labour supply effect. The calculation was made with parameters from Table 1 , page 22 .

the real interest rate, which increases saving desire, and on the other hand directly increases output and thus resources available for investment. This potentially allows higher growth.

In Figure 1b, the intersection of $C C^{\prime}$ and $G G^{\prime}$ at point $A$ lies further to the right the more persistent the shock is, which can easily be seen in equation (22b). A higher responsiveness of labour supply to a fall in consumption makes the $\Delta C / K=0$ curve flatter and thus moves point $B$ right. This implies that there is a larger range for point $A$ to be above $g^{*}$. Intuitively, the larger the increase in labour supply, the larger the increase in output allowing directly more investment, and the larger the increase in the real interest rate, leading to more saving and investment. Both mechanisms combined can increase growth. When labour supply is inelastic, then both of these mechanisms fall away and growth decreases when government spending is not productive.

When government spending is productive $(\gamma>0)$, two effects are at work. The first is the direct positive effect on output and thus investment possibilities, thus shifting $G G^{\prime}$ right. The second is the positive effect on the return to capital, which increases the interest rate and induces higher saving and investment. This shifts both the $\Delta(C / K)=0$ 
right as well as the $C C^{\prime}$ curve further down. Both of these effects increase the growth inducing effect of the increase in labour supply caused by higher government spending. When labour supply is inelastic, then the productive effect of government spending has to be larger in order to induce more growth.

We showed that even in a flexible price endogenous growth model a temporary government spending shock can lead to a positive long run effect on consumption and output under certain conditions, like productive government spending and elastic labour supply. In the next section we will discuss how the analysis is affected by the introduction of New Keynesian price rigidities.

\section{The New Keynesian Adjustments}

\subsection{New Keynesian Extension}

A New Keynesian model is characterised by allowing for temporary deviations from the flexible price equilibrium caused by price stickiness. In line with the literature we assume a Calvo (1983) pricing mechanism, implying that only a certain share, $1-\phi$, of firms can reset their price at the desired mark-up $\mu$ in every period. Since the other firms cannot set their price at the desired constant mark-up above marginal costs, the mark-up and real marginal costs become variable over time. Combining equations (6a) and (6b) by substituting away labour $L$, we can represent real marginal cost of producing one extra unit of output as

$$
m c_{t}=\frac{\left(r_{t}^{k}\right)^{\frac{\alpha-\gamma}{1-\gamma}} w_{t}^{\frac{1-\alpha}{1-\gamma}}}{\left(A \theta^{\gamma}\right)^{\frac{1}{1-\gamma}} \alpha^{\frac{\alpha-\gamma}{1-\gamma}}(1-\alpha)^{\frac{1-\alpha}{1-\gamma}} K_{t}^{\frac{1-\alpha}{1-\gamma}}}
$$

Higher marginal costs will lead to higher inflation $\pi$, as shown by the New Keynesian Phillips curve derived among others by Galí and Gertler (1999).

$$
\hat{\pi}_{t}=\beta \hat{\pi}_{t+1}+\chi \widehat{m c}_{t}
$$

where $\chi=(1-\phi)(1-\beta \phi) / \phi$ and $\phi$ is the share of firms not able to reset price in a certain 
period and $\hat{x}$ denotes the percentage deviation of a variable $x$ from its steady state value.

We furthermore assume a central bank setting the interest rate on the bonds market in reaction to deviations of output and inflation from their flexible price level in a Taylor rule fashion. As we show in Kühn and Muysken (2009), a Taylor rule in an endogenous growth model can be written as

$$
R_{t}=R^{*}+\rho_{\pi}\left(\pi_{t}-\bar{\pi}\right)+\rho_{y}\left(\frac{Y_{t}}{K_{t}}-\overline{\left(\frac{Y}{K}\right)}\right)
$$

where $R^{*}$ is the nominal target interest rate corresponding to the steady state natural

real rate plus target inflation $\bar{\pi}$ and $\overline{\left(\frac{Y}{K}\right)}$ is the target steady state output capital ratio. The output gap is expressed relative to capital, in line with the tradition of endogenous growth models. As we explain in Kühn and Muysken (2009), a positive value of $\rho_{y}$ results since the reaction to the output gap captures variations in the natural real rate of interest, which should be accounted for by a central bank reaction function (Woodford, 2001).

\subsection{New Keynesian Model}

The full model is similar to the flexible price model of section 2.5. There are two differences, however. First, the process for real marginal costs (equation 23) replaces equation (14f). Second, the nominal interest rate is set by the central bank. This means that we additionally have to state equation (11b) explicitly as (26f), which we implicitly used in the flexible price model through its substitution into equation (11a). The full model is therefore: 


$$
\begin{aligned}
\frac{Y_{t}}{K_{t}} & =m c_{t}^{c_{1}}(1-\alpha)^{c_{1}}\left(A \theta_{t}^{\gamma}\right)^{\frac{1}{1-\gamma}\left(1+c_{1}\right)}\left(\frac{C_{t}}{K_{t}}\right)^{-c_{1}}, \\
\frac{C_{t}}{K_{t}} & =\frac{C_{t+1}}{K_{t+1}}\left(1+g_{t+1}\right) \frac{1}{\beta} \frac{1}{1-\delta+r_{t+1}^{k}}, \\
g_{t+1} & =\frac{I_{t}}{K_{t}}-\delta \\
\frac{I_{t}}{K_{t}} & =\left(1-\theta_{t}\right) \frac{Y_{t}}{K_{t}}-\frac{C_{t}}{K_{t}}, \\
m c_{t} & =\left(r_{t}^{k}\right)^{\frac{1}{1+c_{1}}}\left(\frac{C_{t}}{K_{t}}\right)^{\frac{c_{1}}{1+c_{1}}} \alpha^{-\frac{1}{1+c_{1}}}(1-\alpha)^{-\frac{c_{1}}{1+c_{1}}}\left(A \theta_{t}^{\gamma}\right)^{-\frac{1}{1-\gamma}}, \\
r_{t}^{k} & =\frac{R_{t}}{\pi_{t}}+\delta-1, \\
\hat{\pi}_{t} & =\beta \hat{\pi}_{t+1}+\chi \widehat{m c}_{t} \\
R_{t} & =R^{*}+\rho_{\pi}\left(\pi_{t}-\bar{\pi}\right)+\rho_{y}\left(\frac{Y_{t}}{K_{t}}-\overline{\left(\frac{Y}{K}\right)}\right)
\end{aligned}
$$

with

$$
c_{1}=\frac{1-\alpha}{\sigma+\alpha-\gamma(1+\sigma)}>0
$$

\subsection{New Keynesian Dynamics}

To analyse the effects of a temporary government spending shock we linearise the model around its steady state using a first order Taylor approximation. The resulting equations can be seen in Appendix B.1. We use the method of undetermined coefficients to solve the model analytically. Again we use the government spending process from equation 19.

Lemma 4.1 Given a central bank reaction function that perfectly accommodates the nominal interest rate to changes in the natural real rate as they are caused by a change in government spending, implying $\rho_{y}=\frac{\alpha}{\mu} \bar{\pi}$, the New Keynesian model behaves like the flexible price model.

Proof We define $\hat{c}_{t}=\varphi_{1} \hat{\theta}_{t}, \hat{g}_{t+1}=\varphi_{2} \hat{\theta}_{t}$ and $\hat{\pi}_{t}=\varphi_{3} \hat{\theta}_{t}$. The impact responses of these 
variables to a shock in $\theta$ are defined by

$$
\begin{aligned}
\varphi_{1} & =-\frac{B_{13}}{B_{11}-\rho_{\theta}} \frac{u}{u-v}+\frac{B_{23} A_{12}}{u-v} \\
\varphi_{2} & =\frac{1+g}{g}\left[\frac{a_{2} a_{3}}{c_{2}-a_{4}} \varphi_{3}-\left(\frac{a_{1} a_{2}}{c_{2}-a_{4}}+a_{1} a_{2}-\frac{g+\delta}{1+g}\right) \varphi_{1}\right] \\
& -\frac{1+g}{g} \frac{a_{1} a_{2}}{c_{2}-a_{4}}\left(\frac{\theta}{1-\theta}\left(c_{2}-a_{4}\right)-\frac{\gamma}{1-\gamma} c_{2}\right) \\
\varphi_{3} & =-\frac{B_{23}}{B_{22}-\rho_{\theta}} \frac{u}{u-v}+\frac{B_{13} B_{21}}{u-v}
\end{aligned}
$$

with

$$
\begin{aligned}
& u=\left(B_{11}-\rho_{\theta}\right)\left(B_{22}-\rho_{\theta}\right) \\
& v=B_{12} B_{21}
\end{aligned}
$$

Appendix B.1 defines the parameters. Appendix B.2 discusses the signs of $\varphi_{1}$ and $\varphi_{3}$.

When $\rho_{y}=\frac{\alpha}{\mu} \bar{\pi}$ and thus $a_{4}=1$, then the model can be reduced to its flexible price counterpart, since $B_{21}=0$. This implies that equations (27a) and (27b) are equivalent to equations (22a) and (22b).

The economic intuition is that a government spending shock directly affects the flexible price real rate of interest. Since the endogenous growth model does not feature excess demand, full accommodation of a change in the flexible price real interest rate by the central bank leaves actual marginal costs of firms and all other variables at their flexible price level. The response to a government spending shock is then described by lemma 3.2.

Graphically, the setting of the interest rate by the central bank removes the real interest rate effect due to labour supply changes from the $C C$ and the $\Delta(C / K)=0$ curves, making the latter vertical. For a change in government spending to have the same effect as under flexible prices, the central bank has to increase the interest rate as it would happen under flexible prices. In this case the intersection of the $G G$ curve and the $\Delta(C / K)=0$ curve traces the $\Delta(C / K)=0$ curve in Figure $1 \mathrm{~b}$.

Lemma 4.2 If the central bank reacts to deviations in output beyond pure adjustment of the natural real rate of interest $\left(\rho_{y}>\frac{\alpha}{\mu} \pi\right.$, meaning $\left.a_{4}>1\right)$, a temporary government spending shock has more positive effect on growth than described in lemma 3.2. This 
implies a higher chance of consumption crowding in.

Proof The grey area in Figure 2 shows how the parameter range of $\sigma$ and $\gamma$ allowing higher growth $\left(\varphi_{2}>0\right)$ increases when a central bank reaction of $\rho_{y}=0.5$, implying $a_{4}>1$, is used. Further numerical simulations show that $\frac{\partial \varphi_{2}}{\partial a_{4}}>0$.

A strong response of the central bank to deviations in output from its target level $\left(a_{4}>1\right)$ also has the effect of increasing the interest rate and therefore the cost of capital, which increases, due to the capital labour ratio optimality condition ${ }^{11}$, labour demand and thus output. Therefore, $a_{4}>1$ has the same effect on the curves in Figure $1 \mathrm{~b}$ as $\gamma>0$. Both of these effects imply a more positive response of the growth rate to a temporary government spending shock.

When labour supply is inelastic $(\sigma \rightarrow \infty)$, output cannot deviate from its flexible price level since the factors of production are fixed. The only difference between the flexible and sticky price model then arises from a difference in saving desire by households in reaction to the interest rate set by the central bank. When the central bank actively responds to deviations in output from steady state $\left(a_{4}>1\right)$, then a rise in output induced by productive government spending will lead to higher saving and growth compared to the flexible price model. With only unproductive government spending $(\gamma=0)$ there is no difference between the two model versions since output remains unchanged. It should be clear that the removal of the labour supply effect significantly reduces the chance for crowding in.

We showed that the introduction of New Keynesian price stickiness can enhance the growth increasing effect of temporary government spending since output above flexible price level on the one hand directly provides resources for more growth and on the other hand leads, through the central bank reaction function, to a higher interest rate which increases saving, investment and growth. Even though price stickiness is necessary for output to deviate from its flexible price level, it is actually the central bank reaction function that prescribes how much and in what direction it does so.

\footnotetext{
${ }^{11}$ Dividing (6b) by (6a) yields $\frac{K}{L}=\frac{\alpha}{1-\alpha} \frac{w}{r^{k}}$.
} 


\section{Simulation}

This section discusses numerical simulations with realistic parameter choices in order to visualise the consumption crowding in opportunity of our model. We simulate the model using the parameter set in Table 1 . These are standard values following the literature (e.g. Galí et al., 2007). The Taylor rule parameter $\rho_{\pi}$ is in line with Dupor (2001), who found that models with capital accumulation require a non-active interest rate policy for determinacy. The Taylor rule parameter on output is standard in the literature (as in Gerlach and Schnabel, 2000). We set parameter $A$ so as to obtain the annualised steady state growth rate of $3 \%$.

\begin{tabular}{|c|c|c|c|c|c|c|c|c|c|}
\hline$\alpha$ & $\beta$ & $\mu$ & $\delta$ & $\sigma$ & $g$ & $\bar{\pi}$ & $\rho_{\theta}$ & $\rho_{\pi}$ & $\rho_{y}$ \\
\hline 0.33 & 0.99 & 1.1 & 0.025 & 1 & 0.0074 & 1.005 & 0.9 & 1 & 0.5 \\
\hline
\end{tabular}

Table 1: Parameters used for Simulations.

We set the parameter for the productivity effect of government flow spending to $\gamma=0$ and $\gamma=0.1$. We also show the importance of endogenous labour supply by including the results of a fixed labour supply simulation with $\gamma=0.1$.

Simulation makes it furthermore possible to include a government capital stock and simulate the results of a temporary increase in government capital investment to check whether the analytical analysis using productive flow spending yields results that extend to a model with government capital stock dynamics.

We introduce the public capital stock $\left(K_{t}^{G}\right)^{\eta}$ in equation (2). This means that the public capital stock enters the production function, where we calibrate its marginal product to $\eta=0.1$ throughout our whole analysis, in line with the findings by Romp and de Haan (2007). The government capital accumulation equation then is

$$
K_{t+1}^{G}=\left(1-\delta^{G}\right) K_{t}^{G}+I_{t}^{G}
$$

We define, similar to equation 3 for government consumption, government investment as a certain percentage of GDP.

$$
I_{t}^{G}=\theta_{I^{G}} Y_{t}
$$


We calibrate $\theta_{I^{G}}$ to the EU average of $2.4 \%$ (Eurostat). From the government capital

accumulation equation 28 we can derive $\frac{\frac{I^{G}}{Y} \frac{Y}{K}}{\frac{K^{G}}{K}}-g=\delta^{G}$. Using the EU average of the ratio of public to private capital is $39.7 \%$ (Kamps, 2005), we would obtain a negative depreciation rate of public capital, $\delta^{G}$. Therefore, we calibrate $\delta^{G}=7.5 \%$ annually and calculate the implied public to private capital stock ratio. $\theta_{C}$, which is the share of government consumption in GDP, remains at 0.2 .

First, we present the simulated response of private consumption for a number of cases in Section 5.1. Second, we discuss the size of output multipliers in a New Keynesian endogenous growth model and compare them to a standard model in Section 5.2.

\subsection{Private Consumption Response}

We present the results by showing the percentage difference in private consumption as compared to the baseline scenario of no change in government spending, both scaled by baseline GDP. If the line goes above zero, growth increases, when it stays below, growth decreases. The scale is from $-1.5 \%$ to $2 \%$ in all Figures.

Figure 3 shows the timepath of consumption for the model analysed in the paper, that is without a government capital stock. When government spending is not productive, growth is reduced upon a temporary government spending shock of $2 \%$ of GDP, in line with Figure 2. The fall in resources does induce higher labour supply and thus output. However, the dissaving motive of households is too strong, thereby leading to lower growth. The introduction of productive effects of government spending changes that result. In combination with price stickiness significant growth effects occur that increase consumption above its original level within 1 year. When labour supply is fixed, growth falls, showing the importance of the labour supply channel to provide resources for higher growth.

Figure 4 shows the simulated results of an increase in either government capital investment or government consumption, or both, when we include a productive government capital stock. In row 1 we show the effect of an increase in government investment of $1.2 \%$ of GDP. Such a shock leads to an acceleration in private capital accumulation as its productivity increases, which also increases private consumption. Later, the steady state 


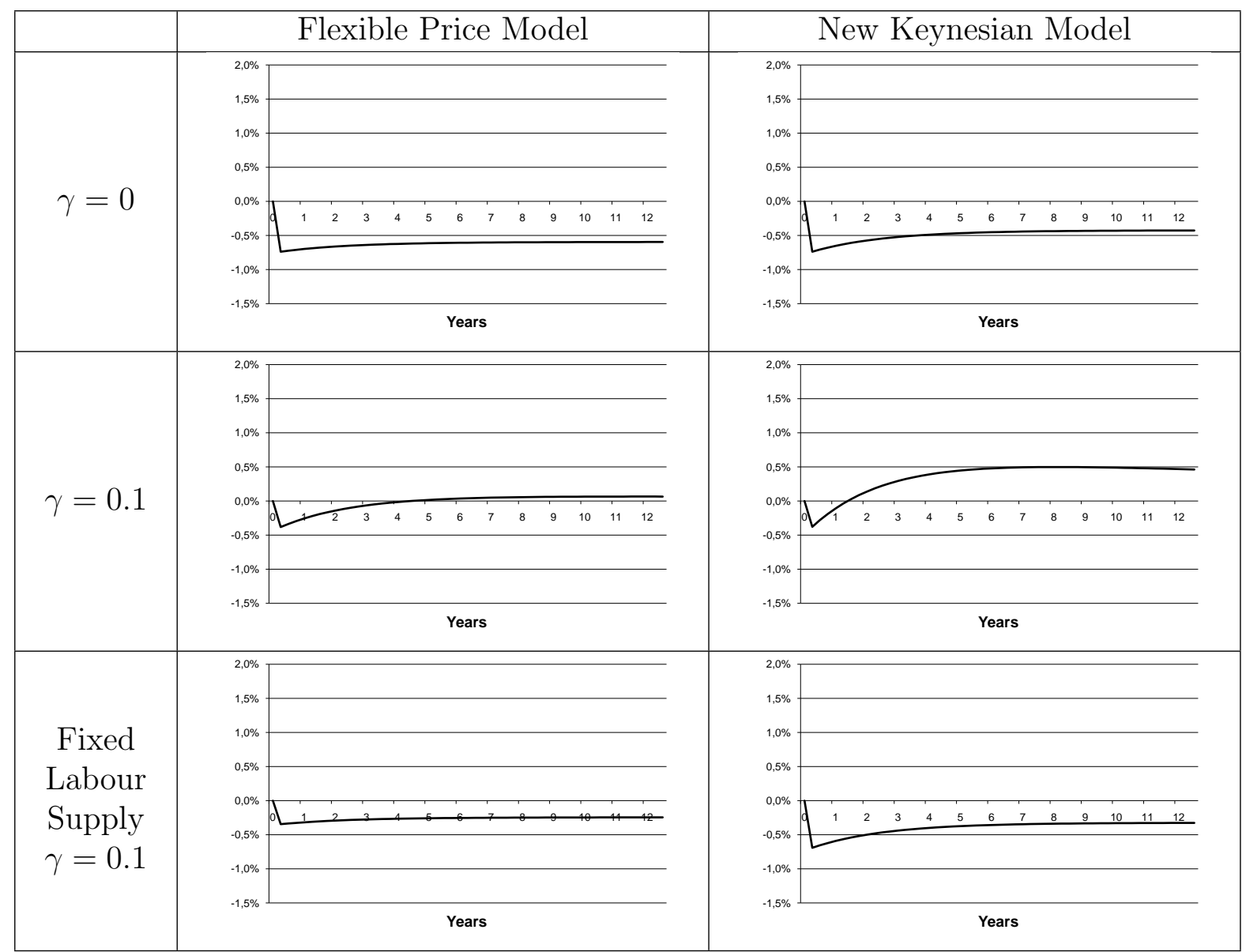

Figure 3: Model with (productive) government flow spending. Development of private consumption as a difference to the baseline scenario of no change in government spending, both scaled by baseline GDP. The shock is a 10\% increase in government spending, corresponding to a $2 \%$ of total GDP. 


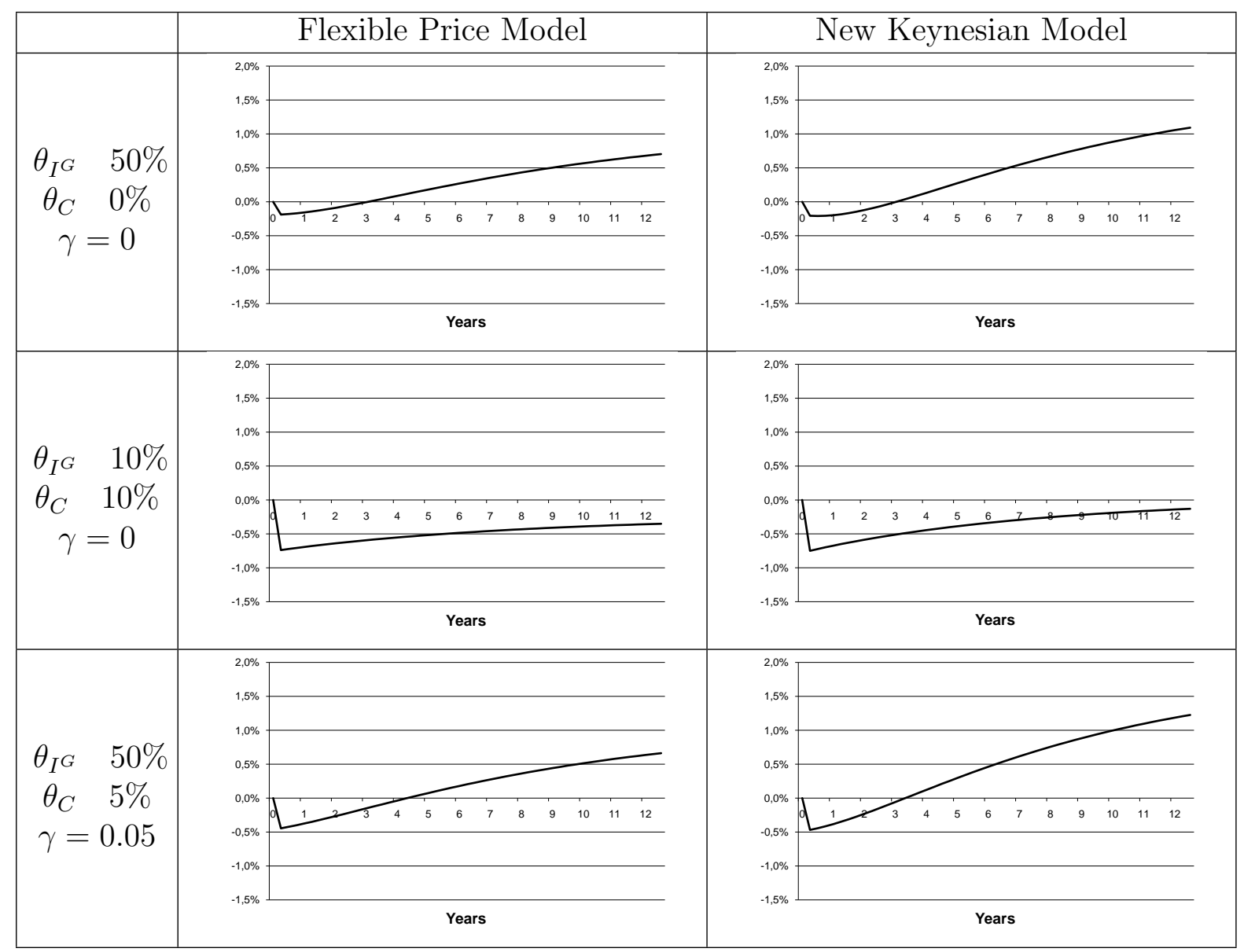

Figure 4: Model with government capital stock. Development of private consumption as a difference to the baseline scenario of no change in government spending, both scaled by baseline GDP. $\theta_{I^{G}} \quad 10 \%$ means a $10 \%$ shock to productive government investment, corresponding to $0.24 \%$ of GDP (where Government capital has a marginal product of $\eta=0.1$.). $\theta_{C} \quad 10 \%$ means a $10 \%$ shock to government consumption, corresponding to $2 \%$ of total GDP. 
growth path is approached again.

In the second row we simulate an across the board increase in government spending. Since we assume government consumption not to be productive, its negative effect on growth, seen in row 1 of Table 3, dominates the positive effect of additional investment, leading to overall lower growth.

Finally, we simulate the model under the assumption that government flow spending also has slight productive effects $(\gamma=0.05)$. The intuition is that the government capital stock considered here is purely physical capital. However, government spending on education, security or other market-relevant services clearly have some productivity enhancing potential. We induce a $1.2 \%$ of GDP increase in government capital investment as well as a $1 \%$ of GDP increase in government consumption. The government consumption component is nearly neutral in terms of the growth effect (see Figure 2), so that these figures are quite similar to row 1, except for the larger negative initial impact on consumption due to the larger size of the spending increase.

The message of the simulation with the government capital stock is that an increase in productive government capital investment has a similar effect as an increase in productive government flow spending, although the effects in the former are more delayed. Nevertheless, the simplification of using productive flow spending for our analytical analysis, allowing clear analytical results, turns out to be legitimate concerning the qualitative results obtained.

\subsection{Government Spending Multipliers}

The recent use of fiscal policy by governments around the world to combat the recession has reignited interest in the effectiveness of government spending. Cogan et al. (2009) correctly note that fiscal policy advice should be based on robust estimates concerning the effects of fiscal policy. More specifically, they remark that there exists a significant gap between government spending multipliers on output between Old Keynesian and New Keynesian models. Romer and Bernstein (2009) report that the short run multipliers of permanent fiscal spending are around unity while long run multipliers are even larger. Cogan et al. (2009) argue that in a DSGE model like the one by Smets and Wouters 
(2007) the impact multipliers are somewhat smaller, while the long-run multipliers are much smaller.

Hall (2009) surveys both empirical and theoretical literature dealing with the government spending multiplier. His Table 2 shows that impact multipliers are estimated in a range of 0.3 to 0.9 , with the multiplier estimates after 2 years being on average larger than impact multipliers. While the standard New Keynesian model can be extended to produce realistic impact multipliers (see Hall, 2009), it cannot reproduce the larger medium run multipliers. The reason is that a short-run boom induced by the government spending shock has no positive long-run effect - in fact, investment is crowded out. With an endogenous growth model the temporary government spending shock, if it leads to more growth, will induce lasting effects.

We add to the debate by showing the effect endogenous growth has on output multipliers in New Keynesian models. We therefore simulate different versions of our model and compare them to a standard New Keynesian model without endogenous growth (implying $\epsilon=0$ ), but with productive government spending. Appendix $\mathrm{C}$ outlines the simulated model.

\begin{tabular}{|c|c|c|c|c|c|}
\hline & & \multicolumn{2}{|c|}{ No Government Capital } & \multicolumn{2}{|c|}{ Government Capital } \\
\hline \multirow[b]{3}{*}{ EG } & \multirow[b]{2}{*}{ impact } & $\gamma=0$ & $\gamma=0.1$ & Par 1 & Par 2 \\
\hline & & 0,37 & 1.03 & $-0,02$ & 0,36 \\
\hline & 2 Years & 0.02 & 0.71 & 0.42 & 0.48 \\
\hline & impact & 0,25 & 0,56 & 0,54 & 0,50 \\
\hline no EG & 2 years & 0.16 & 0.32 & 0.56 & 0.44 \\
\hline
\end{tabular}

Table 2: The output multiplier of government spending on impact and after 2 years in a model with and without endogenous growth. Par 1 means $\gamma=0$, shock to $\theta_{I^{G}}=50 \%$, shock to $\theta_{C}=0 \%$, Par 2 means $\gamma=0.05$, shock to $\theta_{I^{G}}=50 \%$, shock to $\theta_{C}=5 \%$.

Table 2 shows the output multipliers of some selected models we simulated, calculated as the output change over the government spending change in the period of impact. The third row,first column, shows the impact multiplier of a standard New Keynesian model, which is comparable to other results when using our set of parameters (e.g. with the MATLAB code available in the online appendix of Hall (2009)).

The impact multiplier of the endogenous growth model is larger than in the nonendogenous growth model only in the case of productive flow spending. The reason is 
that here the desired growth rate immediately is higher, which raises saving by lowering consumption, which in turn additionally raises labour supply and output. Public capital investment is not productive in the period of impact, but only later. The rational expectations equilibrium prescribes a fall in labour supply in the period of impact, caused by a fall in real wages. However, as soon as capital accumulation starts, there is a significant effect on the output multiplier.

The model Par 2 comes closest to the kind of fiscal policy analysed by Cogan et al. (2009) with a mix of public investment and consumption. The multipliers of the two model versions are quite similar, except for the fact that the endogenous growth model has a larger medium-run multiplier, while for the basic New Keynesian model the impact multiplier is larger. This shows the valuable addition of the endogenous growth channel in the task of reproducing realistic output multipliers. The precise size can be adjusted with the measures described by Hall (2009), a task which we do not perform here.

Another aspect discussed by Cogan et al. (2009) is the response of private consumption and investment. In the model by Smets and Wouters (2007), both are crowded out. However, empirical evidence is not so clear about the effect on both these variables (see references in Section 1). The endogenous growth model provides more flexibility as it allows crowding in of these variables.

\section{Conclusion}

There exists a mismatch between the empirical observation of government spending crowding in private consumption as well as the prediction of the standard RBC and New Keynesian model where private consumption is crowded out by government spending. A number of authors have taken different approaches to deal with that situation, making assumptions on households' utility function or their intertemporal optimisation.

We take a different approach by claiming that government spending produces a growth effect that is able to explain rising consumption, at least in the medium term. We analytically solve an endogenous growth model with endogenous labour supply and show the conditions for government spending to increase the economy's growth rate under flexible prices. 
We show that even in a flexible price model a temporary government spending shock can lead to an increase in private consumption in the medium run when government spending is sufficiently productive. The introduction of price stickiness increases the growth response of the economy and leads to a significant increase in private consumption a short time after the spending shock.

We also simulate a model with a productive government capital stock. It shows that additional government capital investment induces a slower but lasting positive stimulus for the economy's growth rate compared to the model with productive flow spending. Nevertheless, the basic conclusion that government spending crowds in private consumption in the medium run is maintained.

The recent use of fiscal policy has reignited a discussion on the size of government spending multipliers. Multipliers in the New Keynesian endogenous growth model are more in line with empirically observed multipliers than the ones obtained by a standard New Keynesian model. First, medium run output multipliers are relatively high, and second, the multipliers on investment and consumption are not strongly negative, but can also be positive. This shows that fiscal policy analysis should take growth effects into account. Therefore, one should consider the addition of endogenous growth effects to the New Keynesian model when evaluating fiscal policy effects.

\section{References}

Barro, R. (1990). Government spending in a simple model of endogeneous growth. Journal of Political Economy 98(5), 103-125.

Barro, R. J. and X. Sala-i-Martin (1995). Economic Growth. McGraw-Hill.

Baxter, M. and R. G. King (1993). Fiscal policy in general equilibrium. The American Economic Review 83(3), 315-334.

Blanchard, O. and C. Kahn (1980). The solution of linear difference models under rational expectations. Econometrica 48(5), 1305-1311.

Blanchard, O. and R. Perotti (2002). An empirical characterization of the dynamic effects 
of changes in government spending and taxes on output. The Quarterly Journal of Economics 117(4), 1329-1368.

Bom, P. R. and J. E. Lighthart (2008). How productive is public capital? A meta-analysis. CESifo Working Paper Series (2206).

Burnside, C., M. Eichenbaum, and J. Fisher (2004). Fiscal shocks and their concequences. Journal of Economic Theory 115, 89-117.

Calvo, G. A. (1983). Staggered prices in a utility-maximizing framework. Journal of Monetary Economics 12, 383-398.

Castro, F. (2006). The macroeconomic effects of fiscal policy in Spain. Applied Economics 38, 913-924.

Chang, W.-Y. (1999). Government spending, endogenous labor, and capital accumulation. Journal of Economic Dynamics and Control 23, 1225-1242.

Christiano, L., M. Eichenbaum, and S. Rebelo (2009). When is the government spending multiplier large? NBER Working Paper (15394).

Cogan, J. F., T. Cwik, J. B. Taylor, and V. Wieland (2009). New Keynesian verus old Keynesian government spending multipliers. CEPR Discussion Paper (7236).

Dupor, B. (2001). Investment and interest rate policy. Journal of Economic Theory 98, $85-113$.

Galí, J. and M. Gertler (1999). Inflation dynamics: A structural econometric analysis. Journal of Monetary Economics 44(2), 195-222.

Galí, J., J. D. López-Salido, and J. Valles (2007). Understanding the effects of government spending on consumption. Journal of the European Economic Association 5(1), 227270.

Gerlach, S. and G. Schnabel (2000). The Taylor rule and interest rates in the EMU area. Economic Letters 67(2), 165-171. 
Hall, R. E. (2009). By how much does GDP rise if the government buys more output? NBER Working Paper (15496).

Hiroki, A. (2009, May). Long-run relationship between inflation and growth in a New Keynesian framework. Munich Personal RePEc Achive (15205).

Kamps, C. (2005). Is there a lack of public capital in the European Union. EIB Papers $10(1), 72-93$.

Kühn, S. and J. Muysken (2009). Why inflation targeting central banks seem to follow a standard Taylor rule. Meteor Research Memorandum (RM/09/058).

Kühn, S., J. Muysken, and T. van Veen (2009). The adverse effects of government spending on private consumption in New Keynesian models. Metroeconomica, forthcoming.

Linnemann, L. and A. Schabert (2003a). Can fiscal spending stimulate private consumption? Economic Letters 82, 173-179.

Linnemann, L. and A. Schabert (2003b). Fiscal policy in the New Neoclassical Synthesis. Journal of Money, Credit and Banking 35(6), 911-930.

Perotti, R. (2007). In search of the transmission mechanism of fiscal policy. NBER Working Paper (13143).

Rannenberg, A. (2008). Disinflation and the NAIRU in a New-Keynesian New-Growth model. MPRA working paper (9753).

Romer, C. and J. Bernstein (2009, January). The job impact of the american recovery and reinvestment plan.

Romer, P. (1986). Increasing returns and long-run growth. Journal of Political Economy 94(5), 1002-1037.

Romp, W. and J. de Haan (2007). Public capital and economic growth: A critical survey. Perspektiven der Wirtschaftspolitik 8, 6-52.

Smets, F. and R. Wouters (2007). Shocks and frictions in u.s. business cycles: A Bayesian DSGE approach. The American Economic Review 97(3), 506-606. 
Turnovsky, S. J. (1997). Fiscal policy in a growing economy with public capital. Macroeconomic Dynamics 1, 615-639.

Turnovsky, S. J. (2000). Fiscal policy, elastic labour supply and endogenous growth. Journal of Monetary Economics 45, 185-210.

Woodford, M. (2001). The Taylor rule and optimal monetary policy. The American Economic Review 91(2), 232-237.

Woodford, M. (2003). Interest and Prices. Princeton University Press.

\section{APPENDIX}

\section{A Taylor Approximation of the Flexible Price En- dogenous Growth Model}

We make a first order Taylor approximation of the flexible price endogenous growth model of equations $14 \mathrm{a}$ to $14 \mathrm{f}$. We define the steady state percentage deviations of $C / K, g$ and $\theta$ as $\hat{c}, \hat{g}$ and $\hat{\theta}$. We can write our model in the reduced form matrix notation as $X_{t+1}^{f}=A X_{t}^{f}$, where $X^{f}=\left[\begin{array}{ll}\hat{c} & \hat{\theta}\end{array}\right]^{\prime}$. The $2 \times 2$ transition matrix $A$ has the elements

$$
\begin{aligned}
& A_{11}=\frac{\frac{1-\delta}{1+g}\left(c_{2}-1\right)+a_{1} a_{2} c_{2}}{c_{2}-\left(1-a_{1}\right)} \\
& A_{12}=\frac{a_{1} a_{2}\left(\frac{\theta}{1-\theta}\left(c_{2}-1\right)-\frac{\gamma}{1-\gamma} c_{2}\right)+\rho_{\theta} a_{1} \frac{\gamma}{1-\gamma} c_{2}}{c_{2}-\left(1-a_{1}\right)} \\
& A_{21}=0 \\
& A_{22}=\rho_{\theta}
\end{aligned}
$$

with

$$
\begin{aligned}
& a_{1}=1-\beta \frac{1-\delta}{1+g} \\
& a_{2}=\frac{1-\theta}{\beta} \frac{\mu}{\alpha}>1 . \\
& c_{2}=\frac{1}{c_{1}}+1=\frac{(1+\sigma)(1-\gamma)}{1-\alpha}>1
\end{aligned}
$$

Determinacy requires that $A_{11}>1$, which always holds. 


\section{B Taylor Approximation of the New Keynesian En- dogenous Growth Model}

For our analysis we make a Taylor approximation of equations $26 \mathrm{a}$ to $26 \mathrm{f}$ as well as equations 24 and 25. We refer to the deviations from steady state of $C / K, \pi, \theta$ and $g$ as $\hat{c}, \hat{\pi}, \hat{\theta}$ and $\hat{g}$ respectively.

\section{B.1 Reduced Linearised System}

We write the model as

$$
X_{t+1}^{N K}=B X_{t}^{N K}
$$


where $X_{t}^{N K}=\left[\begin{array}{lll}\hat{c} & \hat{\pi} & \hat{\theta}\end{array}\right]^{\prime}$ and the transition matrix $\mathrm{C}$ is a $3 \times 3$ matrix with the elements

$$
\begin{aligned}
B_{11} & =\frac{\frac{1-\delta}{1+g}\left(c_{2}-a_{4}\right)+a_{1} a_{2}\left(c_{2}-a_{4}+1\right)+a_{3} \frac{\pi}{1+\pi} c_{2} B_{21}}{c_{2}-a_{4}\left(1-a_{1}\right)} \\
B_{12} & =\frac{a_{3} \frac{\pi}{1+\pi}\left(c_{2} B_{22}-a_{2}\right)}{c_{2}-a_{4}\left(1-a_{1}\right)} \\
B_{13} & =\frac{a_{1} a_{2}\left(\frac{\theta}{1-\theta}\left(c_{2}-a_{4}\right)-c_{2} \frac{\gamma}{1-\gamma}\right)+a_{3} c_{2} \frac{\pi}{1+\pi} B_{23}+a_{1} a_{4} c_{2} \frac{\gamma}{1-\gamma} \rho_{\theta}}{c_{2}-a_{4}\left(1-a_{1}\right)} \\
B_{21} & =\frac{\chi}{\beta} \frac{a_{4}-1}{c_{2}-a_{4}} \\
B_{22} & =\frac{1}{\beta}-\frac{\chi}{\beta} \frac{a_{3}}{a_{1}} \frac{\pi}{1+\pi} \frac{c_{2}-1}{c_{2}-a_{4}} \\
B_{23} & =-c_{2} \frac{\gamma}{1-\gamma} B_{21} \\
B_{33} & =\rho_{\theta}
\end{aligned}
$$

with

$$
\begin{aligned}
& a_{1}=1-\beta \frac{1-\delta}{1+g}>0 \\
& a_{2}=\frac{1-\theta}{\beta} \frac{\mu}{\alpha}>1 \\
& a_{3}=\frac{\rho_{\pi}}{1+r^{k}-\delta}-1 \\
& a_{4}=\frac{\rho_{y}}{1+\pi} \frac{\mu}{\alpha} \\
& c_{2}=\frac{(1+\sigma)(1-\gamma)}{1-\alpha}>1 .
\end{aligned}
$$




\section{B.2 Prove of Signs of $\varphi_{1}$ and $\varphi_{3}$}

Using the method of undetermined coefficients, we can derive

$$
\begin{aligned}
\varphi_{1} & =-\frac{B_{13}}{B_{11}-\rho_{\theta}} \frac{u}{u-v}+\frac{B_{23} B_{12}}{u-v} \\
\varphi_{2} & =\frac{1+g}{g}\left[\frac{a_{2} a_{3}}{c_{2}-a_{4}} \varphi_{3}-\left(\frac{a_{1} a_{2}}{c_{2}-a_{4}}+a_{1} a_{2}-\frac{g+\delta}{1+g}\right) \varphi_{1}\right] \\
& -\frac{1+g}{g} \frac{a_{1} a_{2}}{c_{2}-a_{4}}\left(\frac{\theta}{1-\theta}\left(c_{2}-a_{4}\right)-\frac{\gamma}{1-\gamma} c_{2}\right) \\
\varphi_{3} & =-\frac{B_{23}}{B_{22}-\rho_{\theta}} \frac{u}{u-v}+\frac{B_{13} B_{21}}{u-v}
\end{aligned}
$$

with

$$
\begin{aligned}
& u=\left(B_{11}-\rho_{\theta}\right)\left(B_{22}-\rho_{\theta}\right) \\
& v=B_{12} B_{21}
\end{aligned}
$$

We introduce the $2 \times 2$ matrix $B^{\prime}$ with the elements $B_{11}, B_{12}, B_{21}$ and $B_{22}$ and the Eigenvalues $\lambda_{1,2}$. The function $u-v$ can be rewritten as

$$
\begin{aligned}
& u-v=\rho_{\theta}^{2}-\rho_{\theta} \underbrace{\left(B_{11}+B_{22}\right)}_{\operatorname{trace}\left(B^{\prime}\right)}+\underbrace{\left(B_{11} B_{22}-B_{12} B_{21}\right)}_{\left|B^{\prime}\right|} \\
& u-v=\rho_{\theta}^{2}-\rho_{\theta}\left(\lambda_{1}+\lambda_{2}\right)+\lambda_{1} \lambda_{2}
\end{aligned}
$$

$u-v$ is a quadratic function in $\rho_{\theta}$ with two nulls at $\lambda_{1}$ and $\lambda_{2}$. Since determinacy requires $\lambda_{1,2}>1$ (according to the Blanchard-Kahn conditions (Blanchard and Kahn, 1980)), while $\rho_{\theta}<1, u-v$ is clearly positive.

We can rewrite

$$
\begin{aligned}
\varphi_{1} & =-\frac{B_{22}-\rho_{\theta}}{u-v} \frac{a_{1} a_{2}\left(\frac{\theta}{1-\theta}\left(c_{2}-a_{4}\right)\right)}{c_{2}-a_{4}\left(1-a_{1}\right)} \\
& +\frac{B_{22}-\rho_{\theta}}{u-v} c_{2} \frac{\gamma}{1-\gamma}\left[\frac{B_{21} a_{3}\left(a_{2}-c_{2} \rho_{\theta}\right)}{\left(B_{22}-\rho_{\theta}\right)\left(c_{2}-a_{4}\left(1-a_{1}\right)\right)}+\frac{a_{1}\left(a_{2}-a_{4} \rho_{\theta}\right)}{c_{2}-a_{4}\left(1-a_{1}\right)}\right]
\end{aligned}
$$

The first term is definitely negative. The second term is most positive when $\rho_{\theta}=0$. The 
sign of $\varphi_{1}$ then depends negatively on the sign of

$$
\left(\frac{\theta}{1-\theta}\left(c_{2}-a_{4}\right)-c_{2} \frac{\gamma}{1-\gamma}\right)-\frac{a_{3}}{a_{1}} \frac{B_{21}}{B_{22}} c_{2} \frac{\gamma}{1-\gamma}
$$

The first bracket is negative when the GG curve shifts right. In this case the direct productivity effect of government spending is stronger than the negative resource effect. The second term shows the New Keynesian effect of output being possibly above its steady state level, which requires $a_{4}>1$. This additionally shifts the GG-curve. Since under $\rho_{\theta}=0$ the CC-curve does not shift down, $\varphi_{1}>0$ is possible. However, we use realistic parameterisations where the direct productivity effect is not that big, as well as where government spending shocks are persistent. Therefore, $\varphi_{1}<0$ will hold.

We can rewrite

$$
\begin{aligned}
\varphi_{3} & =\frac{B_{21}}{u-v}\left(c_{2} \frac{\gamma}{1-\gamma}\left(B_{11}-\rho_{\theta}\right)+B_{13}\right) \\
\varphi_{3} & =\frac{B_{21}}{u-v} \frac{c_{2}-a_{4}}{c_{2}-a_{4}\left(1-a_{1}\right)}\left[a_{1} a_{2} \frac{\theta}{1-\theta}+c_{2} \frac{\gamma}{1-\gamma}\left(a_{1} a_{2}-\frac{g+\delta}{1+g}+1-\rho_{\theta}\right)\right]
\end{aligned}
$$

Since the bracket is always positive, the sign of $\varphi_{3}$ depends on the sign of $B_{21}$ and thus on the sign of $a_{4}-1$.

\section{The standard New Keynesian Model}

We use equations 4, 9 and 10a. We introduce capital accumulation costs in line with standard New Keynesian literature as specified in Christiano et al. (2009), so that the capital accumulation equation 10b becomes

$$
K_{t+1}=(1-\delta) K_{t}+I_{t}-\frac{\sigma_{I}}{2}\left(\frac{I_{t}}{K_{t}}-\delta\right)^{2} K_{t}
$$

We furthermore use the standard New Keynesian Phillips curve 24 as well as the Taylor Rule

$$
\hat{R}_{t}=\rho_{\pi} \hat{\pi}_{t}+\rho_{y} \hat{y}_{t}
$$


The relationship between the real return to capital and the real return on bonds (determined by the central bank) is given by

$$
1+r_{t+1}^{k}-\delta=\frac{R_{t+1}}{\pi_{t+1}} \frac{1}{1-\sigma_{I}\left(\frac{I_{t}}{K_{t}}-\delta\right)}-\frac{\frac{\sigma_{I}}{2}\left(\frac{I_{t+1}}{K_{t+1}}-\delta\right)^{2}+\sigma_{I}\left(\frac{I_{t+1}}{K_{t+1}}-\delta\right)}{1-\sigma_{I}\left(\frac{I_{t+1}}{K_{t+1}}-\delta\right)}
$$

Without capital adjustment costs, $\sigma_{I}=0$, this equation equals equation $11 \mathrm{~b}$. Current higher investment increases required next period's return to capital due to the cost incurred of installing the capital. Higher future cost of installing capital lowers required return. The intuition is indirect since more installed capital in period $t+1$ will lower future adjustment costs.

Investment is determined via the capital accumulation equation, while the desired future capital stock $\left(K_{t+1}\right)$ is determined via the $M P K$ relation using $r_{t+1}^{k}$. Further equations are the resource constraint, the government capital accumulation equation 28 , equations 11a, 11c as well as $M P L$. These determine a complete equilibrium, which we simulate using first order Taylor approximations. We use the parameter set as defined in Table 1, with the difference that with capital adjustment costs the Taylor rule exhibits normal stability characteristics in the sense that $\rho_{\pi}=1.5$ can be used. $\rho_{y}=0.5$ is still used. Furthermore, we set the investment adjustment cost parameter $\sigma_{I}=17$, following Christiano et al. (2009). 